\title{
Men With Brugada-Like Electrocardiogram Have Higher Risk of Prostate Cancer
}

\author{
Daisuke Haruta, MD*,**,*; Kiyotaka Matsuo, MD*,**,*; Shinichiro Ichimaru, MS**; \\ Midori Soda, MD ${ }^{\dagger}$; Ayumi Hida, MD**; Nobuko Sera, MD**; Misa Imaizumi, MD**; \\ Eiji Nakashima, $\mathrm{PhD}^{\dagger \dagger}$; Shinji Seto, $\mathrm{MD}^{*, * *}$; Masazumi Akahoshi, MD**
}

\begin{abstract}
Background Elevated plasma testosterone levels are thought to play a role in the male preponderance of cases of Brugada syndrome (BS) and the development of prostate cancer.

Methods and Results The 34 Brugada-like electrocardiogram (ECG) cases were identified among 2,681 male survivors of the atomic bomb who had undergone at least 1 biennial health examination between July 1958 and December 1999 in Nagasaki, Japan. They were followed for incident prostate cancer from July 1958 through December 2004, and the risk of prostate cancer for Brugada-like ECG, age, smoking habit, and radiation exposure was analyzed using Cox proportional hazards analysis. Among the men with or without Brugada-like ECG there were $4(11.8 \%)$ and $54(2.0 \%)$ cases of prostate cancer, respectively. With age adjustment there was a higher risk of prostate cancer for Brugada-like ECG (relative risk (RR): 5.42, 95\% confidence interval (CI) 1.96-15.00, $\mathrm{P}=0.001$ ). With further adjustment for smoking habit and radiation dose, Brugada-like ECG remained a significant risk factor for prostate cancer (RR: 6.47, 95\%CI 1.97-21.21, P=0.002).

Conclusions Brugada-like ECG confers a higher risk of prostate cancer independent of age, smoking habit, and radiation exposure. Men with a Brugada-like ECG should be regularly examined for prostate cancer and vice versa, especially elderly subjects. (Circ J 2009; 73: 63-68)
\end{abstract}

Key Words: Brugada-like ECG; Epidemiology; Prostate cancer

B rugada syndrome (BS) is characterized by a covedtype or type 1 ST-segment elevation in the right precordial leads ( $\left.\mathrm{V}_{1-3}\right)$ of the 12-lead electrocardiogram (ECG), as well as symptoms such as documented ventricular fibrillation (VF), polymorphic ventricular tachycardia (VT), family history of sudden death, coved-type ECGs in family members, inducibility of polymorphic VT or VF with programmed electrical stimulation, syncope, or nocturnal agonal respiration!, ${ }^{1,2}$ Several mutations in SCN5A, the $\alpha$ subunit of the sodium channel, have been linked to BS, ${ }^{3-5}$ which displays an autosomal dominant mode of transmission with low penetrance. Although BS is inherited with equal frequency by men and women, most of the reported cases have been in adult men, 6,7 In 2 reported cases of Brugada-like ECG, the typical pattern of coved-type ST elevation disappeared following surgical castration for prostate cancer? Men with BS have significantly higher plasma testosterone levels than age-matched male controls? which suggests that testosterone may contribute to the BS phenotype.

(Received July 15, 2008; revised manuscript received August 21, 2008; accepted August 26, 2008; released online November 29, 2008)

*Department of Cardiovascular Medicine, Course of Medical and Dental Sciences, Graduate School of Biomedical Sciences, Nagasaki University, Departments of **Clinical Studies and Epidemiology, Radiation Effects Research Foundation, Nagasaki, ${ }^{\dagger}$ Department of Statistics, Radiation Effects Research Foundation, Hiroshima and * Saikakai Shibatachokodo Hospital, Shimabara, Japan

Mailing address: Daisuke Haruta, MD, Department of Clinical Studies, Radiation Effects Research Foundation, 1-8-6 Nakagawa, Nagasaki 850-0013, Japan. E-mail: harutad@ rerf.or.jp

All rights are reserved to the Japanese Circulation Society. For permis-

sions, please e-mail: cj@j-circ.or.jp

\section{Editorial p 35}

There is evidence to suggest that testosterone also plays a pathophysiological role in the etiology of prostate cancer. Testosterone is essential for normal growth and maintenance of the prostate, but it also stimulates the proliferation of human prostate cancer cells in vitro and produces prostate cancer in rodents!10,11 Thus, we examined the relationship between the Brugada-like ECG with either the covedtype or saddle-back-type ST elevation and prostate cancer.

\section{Methods}

General Procedures

A total of 7,564 atomic bomb survivors (3,374 men; 4,190 women) have been followed biennially in Nagasaki, Japan since July 1, 1958 as part of a follow-up program conducted by the Radiation Effects Research Foundation (RERF). Detailed descriptions of the program have been published elsewhere!2,13 Each examination includes a physical check-up, 12-lead ECG, and blood pressure measurement by sphygmomanometer while the subjects are seated after resting for at least $5 \mathrm{~min}$. First and fifth Korotkoff phases, respectively, are used for the systolic and diastolic blood pressure (SBP and DBP) readings. Standing height (m) and body weight $(\mathrm{kg})$ are measured without socks or outer clothing and the body mass index (BMI: $\mathrm{kg} / \mathrm{m}^{2}$ ) is calculated. Blood is sampled from a cubital vein for determination of serum cholesterol $(\mathrm{mg} / \mathrm{dl})$ and hemoglobin $(\mathrm{g} / \mathrm{dl})$. At each examination up to 12 clinical diagnoses are made and stored in a database using the International Classification of Disease (ICD) $7^{\text {th }}, 8^{\text {th }}, 9^{\text {th }}$ and $10^{\text {th }}$ editions. 
Table 1 Number of Subjects With Data Allowing Adjustment for Age Only, Age and Smoking Habit, and Age, Smoking Habit, and Radiation Dose

\begin{tabular}{lccc}
\hline \hline & Age only & Age and smoking habit & $\begin{array}{c}\text { Age, smoking habit, } \\
\text { and radiation dose }\end{array}$ \\
\hline Cases with Brugada-like ECG & & & \\
With PC & $4(11.8 \%)$ & $4(12.5 \%)$ & $3(16.7 \%)$ \\
Without PC & 30 & 28 & 15 \\
$\quad$ Total & 34 & 32 & 18 \\
Cases without Brugada-like ECG & & & \\
With PC & $54(2.0 \%)$ & $54(2.2 \%)$ & 1,400 \\
Without PC & 2,593 & 2,379 & 1,436 \\
Total & 2,647 & 2,433 & 1,454 \\
Total & 2,681 & 2,465 & \\
\hline
\end{tabular}

ECG, electrocardiogram.

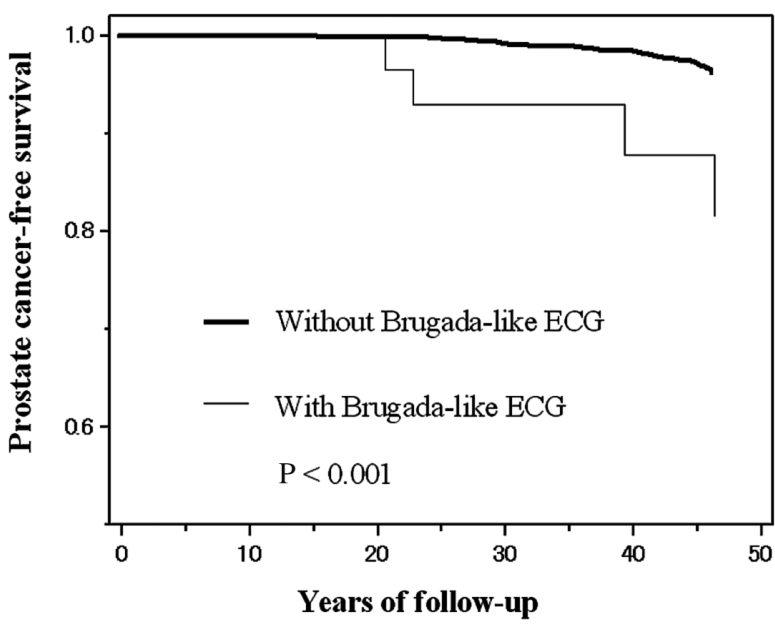

Fig 1. Kaplan-Meier plots showing prostate cancer-free survival, which was lower in cases of Brugada-like electrocardiogram (ECG) than in cases without Brugada-like ECG $(\mathrm{P}<0.001)$.

Smoking habit was investigated several times by mail questionnaire and interview during 1963 and 1991; current and past smokers were both regarded as smokers. The present study was approved by the Research Protocol Review and Human Investigation Committees of RERF.

Study Population and Definition of the Brugada-Like ECG

Of the 3,374 men, we investigated 2,681 who had been examined at least once between July 1, 1958 and December 31, 1999. We characterized the ECG as Brugada-like if it showed the following at least once during the follow-up period: (1) terminal r'wave in lead $\mathrm{V}_{1}$, characterizing right bundle branch block; (2) convex curve or coved-type STsegment elevation $\geq 0.1 \mathrm{mV}$ in lead $\mathrm{V}_{1}$ or in leads $\mathrm{V}_{1}$ and $\mathrm{V}_{2}$; or (3) saddle-back-type ST-segment elevation $\geq 0.1 \mathrm{mV}$ in lead $V_{2}$ or $V_{3}$, or both. One of the authors (K.M.) made the diagnosis of Brugada-like ECG according to these criteria and this was confirmed by 2 other cardiologists who reviewed the records on which the judgment had been made. We identified 34 cases of Brugada-like ECG, which included 6 cases of unexpected death and 3 cases of syncope, leaving 2,647 men without evidence of Brugada-like ECG. Some aspects of the results were reported previously, $6,8,14$ Type 1 ST segment elevation characterized by a coved-type ST elevation $\geq 0.2 \mathrm{mV}$ is included in the diagnostic criteria of BS, whereas Types 2 and 3 ST-segment elevation characterized by a saddle-back ST elevation are not? However, to examine the relationship between Brugada-like ECG and prostate cancer, we used wide criteria that included a saddle-back-type ST elevation and elevation $\geq 0.1 \mathrm{mV}$.

\section{Confirmation of Prostate Cancer}

We identified incident cases of prostate cancer between July 1, 1958 and December 31, 2004 using information from 3 sources. Diagnoses made at biennial health examinations were recorded using ICD codes, as described previously. We followed the vital status of all participants using Japan's family registration system; death certificates were collected for all deceased participants, and prostate cancer as a primary cause of death was recorded according to the coding rules of ICD $7^{\text {th }}, 8^{\text {th }}, 9^{\text {th }}$, and $10^{\text {th }}$ editions. The Nagasaki Prefectural Cancer Registry collected and recorded cancer information according to the ICD for Oncology, 1st, $2^{\text {nd }}$, and $3^{\text {rd }}$ editions. The use of the data of the Nagasaki Prefectural Cancer Registry until 2004 is approved by the Ethics Committee of the Nagasaki Prefectural Cancer Registry. One of the authors (D.H.) reviewed all information from the clinical diagnoses, tumor registry, and death certificates. Prostate cancer cases diagnosed by autopsy only were excluded. In this way 58 cases were ascertained. We defined the date of diagnosis of prostate cancer as follows: (1) in 46 cases of histological examination: the date of histological confirmation; (2) in 12 cases of hormone therapy without histological examination: the date when the clinical diagnosis was made based on digital rectal examination, prostate-specific antigen (PSA) value, and/or bone scintigraphy. Follow-up began in July 1, 1958 and ended on the date of diagnosis of prostate cancer, date of migration or death, or December 31, 2004, whichever came first. Men who died or migrated without a diagnosis of prostate cancer were treated as censored.

\section{Radiation Dose}

Because the radiation dose to the prostate is not estimated in the dosimetry system 2002 (DS02) 15 we used the dose to the urinary bladder as a surrogate. The radiation dose in weighted Gray (Gy) equivalents was calculated using a relative biological effectiveness of 10 for neutrons: gamma dose plus 10 times the neutron dose. The gamma and neutron doses were adjusted for $35 \%$ random error and truncated at $4 \mathrm{~Gy}^{16,17}$ to correct for measurement-error bias because of uncertainties in the estimated doses.

\section{Statistical Analyses}

At first, Kaplan-Meier analysis was used to assess prostate cancer-free survival between subjects with and without 
Table 2 Hazard Ratio (95\% CI) of PC for Brugada-Like ECG After Adjustment for Age, Smoking Habit, and Radiation Dose

\begin{tabular}{lccc}
\hline \hline & \multicolumn{3}{c}{ Factors adjusted } \\
\cline { 2 - 4 } & Age only $(n=2,681)$ & $\begin{array}{c}\text { Age and smoking habit } \\
(n=2,465)\end{array}$ & $\begin{array}{c}\text { Age, smoking habit, } \\
\text { and radiation dose } \\
(n=1,454)\end{array}$ \\
\hline Brugada-like ECG & $5.42(1.96-15.00)$ & $5.76(2.08-15.96)$ & $6.47(1.97-21.21)$ \\
Age at start of follow-up* & $P=0.001$ & $P<0.001$ & $P=0.002$ \\
Smoking habit & $2.53(1.98-3.23)$ & $2.42(1.89-3.09)$ & $2.54(1.88-3.44)$ \\
Radiation dose $(G y)$ & $P<0.001$ & $P<0.001$ & $P<0.001$ \\
& & $0.55(0.31-0.97)$ & $0.56(0.28-1.13)$ \\
& & $P=0.04$ & $P=0.11$ \\
& & $2.12(1.39-3.22)$ \\
\end{tabular}

*Age was transformed as (age at July 1958-15)/10.

CI, confidence interval. Other abbreviations see in Table 1.

Table 3 Basic Characteristics at the Most Recent Examination Prior to Diagnosis of PC

\begin{tabular}{lccc}
\hline \hline & $\begin{array}{c}\text { PC with Brugada-like } \\
\text { ECG }(n=4)\end{array}$ & $\begin{array}{c}\text { PC without Brugada-like } \\
\text { ECG }(n=46)^{*}\end{array}$ & P value \\
\hline Age at diagnosis of PC (years) & $72.3 \pm 5.8(n=4)$ & $74.2 \pm 7.6(n=46)$ & 0.56 \\
SBP $(\mathrm{mmHg})$ & $144.5 \pm 25.2(n=4)$ & $141.0 \pm 24.8(n=45)$ & 0.73 \\
DBP $(\mathrm{mmHg})$ & $78.5 \pm 10.4(n=4)$ & $78.6 \pm 12.7(n=45)$ & 1.00 \\
Height $(\mathrm{cm})$ & $160.9 \pm 6.9(n=4)$ & $160.2 \pm 6.4(n=41)$ & 0.77 \\
Weight $(\mathrm{kg})$ & $54.5 \pm 7.7(n=4)$ & $55.5 \pm 9.5(n=41)$ & 0.89 \\
BMI $\left(\mathrm{kg} / \mathrm{m}^{2}\right)$ & $20.9 \pm 1.3(n=4)$ & $21.6 \pm 2.7(n=41)$ & 0.57 \\
Serum cholesterol $(\mathrm{mg} / \mathrm{dl})$ & $184.5 \pm 29.7(n=4)$ & $188.2 \pm 27.7(n=44)$ & 0.97 \\
Hemoglobin $(\mathrm{g} / \mathrm{dl})$ & $14.6 \pm 0.7(n=4)$ & $13.7 \pm 1.4(n=46)$ & 0.19 \\
Smoking habit $(\%)$ & $100(n=4)$ & $70.0(n=46)$ & 0.57 \\
Radiation dose $(\mathrm{Gy})$ & $0.52 \pm 0.45(n=3)$ & $0.68 \pm 0.64(n=33)$ & 0.82 \\
\hline
\end{tabular}

Variables are mean $\pm S D$.

*Eight cases among the 54 subjects without Brugada-type ECG were excluded because the period between the most recent examination and diagnosis of $P C$ was more than 2 years.

SBP, systolic blood pressure; DBP, diastolic blood pressure; BMI, body mass index. Other abbreviations see in Table 1.

Brugada-like ECG. Cox regression analysis assuming proportional hazards was used to estimate the prostate cancer incidence rate ratio (relative risk (RR)) and 95\% confidence interval (CI) for the Brugada-like ECG. Survival time is the time from inception of the study to the onset of prostate cancer or censoring. Because we cannot check the proportionality assumption for this data because the number of failures is too small, we assumed that the proportional hazard assumption holds for this data. We adjusted for age at the start of follow-up ([age at July 1958-15]/10) using all 2,681 subjects (Table 1). Smoking habit was unknown in 216 subjects, resulting in 2,465 subjects for adjustment by both age and smoking habit (Table 1). We excluded subjects with unknown dose or who were not in Hiroshima or Nagasaki at the time of the bombing, leaving 1,454 subjects for simultaneous adjustment by age, smoking habit, and radiation dose (Table 1).

To assess the basic characteristics of the cases of prostate cancer with Brugada-like ECG, we compared prostate cancer cases with and without Brugada-like ECG using the Wilcoxon rank-sum test or Fisher's exact test, as appropriate, for age at diagnosis of prostate cancer, SBP, DBP, height, BMI, serum cholesterol, and hemoglobin recorded at the last examination prior to diagnosis of prostate cancer, smoking habit, and radiation dose. All analyses were conducted using SAS for UNIX (SAS Institute, Cary, NY, USA).$^{18}$ The data are expressed as mean \pm SD. A P-value less than 0.05 was considered statistically significant.

\section{Results}

Prostate cancer occurred in $4(11.8 \%)$ of 34 men with, and $54(2.0 \%)$ of 2,647 men without, Brugada-like ECG (Table 1). In the Kaplan-Meier analysis, prostate cancerfree survival was lower in men with the Brugada-like ECG $(\mathrm{P}<0.001)$ (Fig 1). Hazard ratios with the 3 stages of adjustment (age only; age and smoking habit; and age, smoking habit, and radiation dose) are shown in Table 2. Brugadalike ECG was significantly associated with prostate cancer, even after adjustment for age, smoking habit, and radiation dose, although the number of prostate cancer cases among the Brugada-like ECG cases was not so large. There was no interaction of Brugada-like ECG with radiation dose (joint RR: $0.70,95 \%$ CI 0.11-4.38, P=0.70). Smoking habit was negatively associated with prostate cancer in the analysis excluding radiation, but was not significant when radiation dose was included. Radiation dose was a significant risk factor for prostate cancer, even with adjustment for age, smoking, and Brugada-like ECG.

As shown in Table 3, there were no differences between the cases of prostate cancer with and without Brugada-like ECG in terms of the variables examined, which suggests that prostate cancer patients do not have clinical or laboratory characteristics that are specific to Brugada-like ECG.

Of the 4 men with prostate cancer and Brugada-like ECG, 2 underwent surgical castration without prostatectomy at ages 67 in 1979 and 78 in 1981, respectively; another under- 
Table 4 Age and Date at Diagnosis and Therapeutic Procedure for PC in Cases With or Without Brugada-Like ECG

\begin{tabular}{lccc}
\hline \hline$P C$ & Age at diagnosis & Date at diagnosis & Therapeutic procedure \\
\hline With Brugada-like ECG $(n=4)$ & & & \\
Case 1 & 67 & 1979 & Surgical castration \\
Case 2 & 78 & 1981 & Surgical castration \\
Case 3 & 68 & 1997 & Prostatectomy with \\
& & & hormonal castration \\
Case 4 & 77 & 2004 & Hormonal castration \\
Mean \pm SD & $72.3 \pm 5.8$ & $1991 \pm 13$ & Surgical castration $(n=8)$ \\
Without Brugada-like ECG $(n=54)$ & $74.6 \pm 7.7$ & $1994 \pm 9$ & Prostatectomy with \\
& & & hormonal castration $(n=3)$ \\
& & & Hormonal castration $(n=22)$ \\
& & & Prostatectomy $(n=5)$ \\
& & & Unknown $(n=16)$
\end{tabular}

Abbreviations see in Table 1.

Case1 Case3

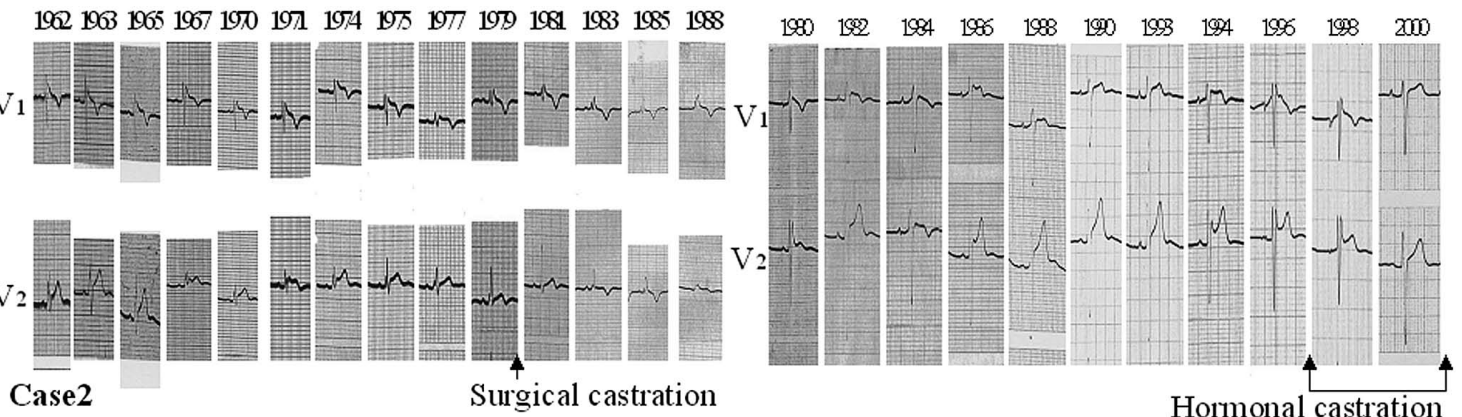

Case2

Surgical castration

Hormonal castration

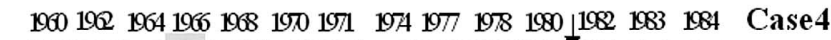

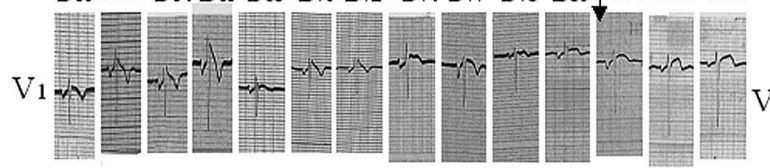

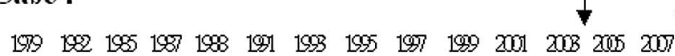

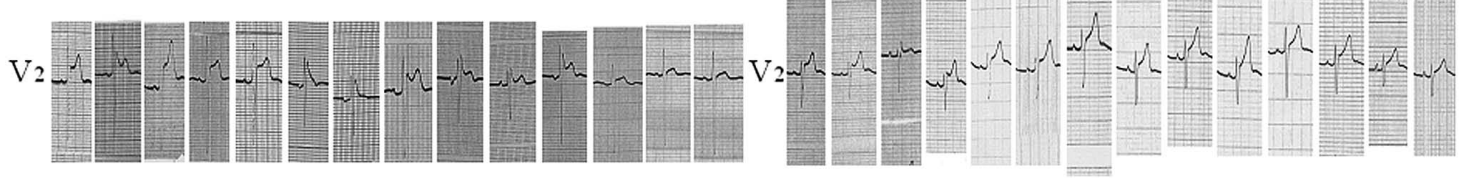

Fig 2. Electrocardiogram (ECG) leads $\mathrm{V}_{1}$ and V2. Case 1: In 1962, a 49-year-old Japanese man showed the Brugada-like ECG on his $1^{\text {st }}$ examination and it persisted until 1979; the most typical Brugada-like ECG with the coved-type ST elevation in leads $\mathrm{V}_{1}$ and $\mathrm{V}_{2}$ was observed in 1971. ST elevation, which was elevated at $0.1 \mathrm{mV}$ in lead $\mathrm{V}_{1}$ in 1979 , disappeared after surgical castration in 1980. He died in 1989 at the age of 76. Case 2: In 1960, a 57-year-old Japanese man had his first examination, and in 1962 his ECG showed the Brugada-like ECG, which persisted until 1980, and the most typical Brugada-like ECG with the coved-type ST elevation in leads V1 and V2 was observed in 1970. The Brugada-like ECG of the RSr' pattern with the coved-type ST elevation in lead $\mathrm{V}_{1}$ and the saddle-back-type in lead $\mathrm{V}_{2}$ disappeared after surgical castration in 1981. He died in 1985 at the age of 82. Case 3: In 1979, a 50-year-old Japanese man had his first examination, and in 1980 he had the Brugada-like ECG. The Brugada-like ECG with the coved-type ST elevation in lead V1 and the saddle-back type ST elevation in lead V2 was observed in 1996. The Brugada-like ECG gradually disappeared from 1998 to 2000 after the initiation of hormonal castration for prostate cancer in 1997. Because the ECGs in 1990 and 1993 were almost normal, it is possible that this change was just an intermittent normalization. He died in 2001 at the age of 72. Case 4: In 1979, a 52-year-old Japanese man had the Brugada-like ECG on his 1 ${ }^{\text {st }}$ examination. The Brugada-like ECG with the coved-type ST elevation in lead $\mathrm{V}_{1}$ and the saddle-back-type ST elevation were observed in 1979 and 1985, respectively. In the other ECGs, the Brugada-like ECG has been unclear. He is alive in 2007.

went prostatectomy and hormonal castration with monthly subcutaneous injection of leuprorelin acetate, an LH-RH agonist, and daily oral administration of bicalutamide, an antiandrogen agent since the age of 68 in 1997; and the $4^{\text {th }}$ underwent hormonal castration without prostatectomy, receiving monthly subcutaneous injection of leuprorelin acetate and daily oral administration of bicalutamide since the age of 77 in 2004 (Table 4). We have already reported that the Brugada-like ECG pattern with coved-type ST ele- vation disappeared after surgical castration in cases 1 and 2 (Fig 2). In case 3, the Brugada-like ECG pattern disappeared after hormonal castration (Fig 2). In case 4, the PSA level decreased from 57.5 (normal range: $1.0-4.0 \mathrm{ng} / \mathrm{ml}$ ) to an undetectable level $(<0.5 \mathrm{ng} / \mathrm{ml})$. However, we could not confirm that disappearance of the Brugada-like ECG pattern was related to hormonal castration because the pattern had been unclear before the initiation of hormonal therapy (Fig 2). 


\section{Discussion}

In the present study, Brugada-like ECG with either coved-type or saddle-back-type ST elevation was significantly associated with prostate cancer risk independently of radiation dose. Thus, this association in male atomic bomb survivors is apparently not mediated through radiation exposure, so the present results may be generalized to men who have not been exposed to radiation.

The association between smoking habit and prostate cancer is equivocal; 1 study reported a positive association, ${ }^{19}$ another a negative association ${ }^{20}$ and still another no association. ${ }^{21}$ Our finding of a positive association between radiation dose and prostate cancer is contrary to 2 previous studies based on atomic bomb survivors?22,23 In those studies, follow-up beginning in 1958 was continued through 1987 and 1998, respectively, whereas the present follow-up continued through 2004. In recent years, PSA measurement has been widely used for prostate cancer screening, so the relative frequency of prostate cancer diagnosis in the present study (58 prostate cancer cases among 2,681 subjects) was higher than in the study based on follow-up through 1998, which included 387 prostate cancer cases among 42,902 subjects. Greater statistical power resulting from a higher incidence rate may explain in part why we observed an association between radiation dose and prostate cancer.

Recent studies have suggested that the preponderance of males with BS might be attributable to testosterone level. Matsuo et al reported that Brugada-like ECG with covedtype ST elevation disappeared after surgical castration for prostate cancer in 2 cases. Shimizu et al reported that men with BS had significantly higher plasma testosterone levels and showed a strong positive association between BS and hypertestosteronemia? Yan and Antzelevitch demonstrated that loss of the action potential dome in the epicardium, but not in the endocardium, induced by potassium channel opener causes Brugada-type ECG ${ }^{24}$ By blocking the transient outward potassium current, the epicardial plateau phase is recovered and the ST segment normalizes. Several studies have demonstrated that testosterone increases the outward potassium current or decreases the inward L-type calcium current $24-27$ These reports suggest that high testosterone levels may contribute to the BS phenotype.

There is evidence to suggest that testosterone plays a pathophysiological role in the etiology of prostate cancer. Testosterone is essential for the normal growth and maintenance of the prostate, stimulates the proliferation of human prostate cancer cells in vitro, and when given in large amounts, can produce prostate cancer in rodents 10,11 Eunuchs, on the other hand, rarely develop prostate cancer and ablation of the testosterone-producing cells frequently results in regression of prostate cancer $28 \mathrm{~A}$ high level of circulating testosterone and a low level of sex hormone binding globulin are associated with increased risk of prostate cancer $2^{29}$ Dehydrotestosterone (DHT), formed by the action of $5 \alpha$-reductase on testosterone, is believed to be the principal intraprostatic androgen, and finasteride, an inhibitor of $5 \alpha$-reductase, reduces prostate cancer risk 30 Testosterone and DHT may be associated with the development of prostate cancer, so we believe that hypertestosteronemia may play a pathophysiological role in both Brugada-like ECG manifestation and prostate cancer, leading to the higher risk of prostate cancer in men with the Brugada-like ECG.

Prostate cancer has been detected more frequently in the early stages of development since the initiation of PSA screening and radical surgical prostatectomy is often performed. Epidural anesthesia using bupivacaine is sometimes used for surgery in early stage prostate cancer and the characteristic coved-type ST elevation is induced by bupivacaine 31 which causes greater depression of the rapid phase of depolarization in Purkinje fibers and ventricular muscle than lidocaine and remains bound to the sodium channels for a longer period of time 32 Thus, because we were unable to clarify the clinical and laboratory characteristics of cases of prostate cancer with Brugada-like ECG, it should be carefully ascertained whether the Brugada-like ECG pattern is present before surgery to avoid iatrogenic accidents during epidural anesthesia.

No effective therapeutic strategy exists to prevent VF in BS. An implantable defibrillator is the established therapy to prevent sudden death in symptomatic patients. Among the present cases of Brugada-like ECG pattern with prostate cancer, the Brugada-like ECG disappeared after surgical castration in 2 cases, as reported previously? With respect to the 2 hormonal castration cases, we confirmed the disappearance of Brugada-like ECG pattern after hormonal castration in 1 case, but were unable to confirm the effect of hormonal castration on the Brugada-like ECG pattern in another. Because the manifestation of the Brugada-like ECG pattern is associated with testosterone ${ }^{8,24-27}$ and BS patients have higher plasma testosterone levels, it is important to accumulate more evidence of the Brugada-like ECG pattern disappearing after testosterone deprivation therapy in men with Brugada-like ECG or BS with prostate cancer treated by hormonal castration, which is preferable to surgical castration. This may provide clues to a new therapeutic strategy to prevent $\mathrm{VF}$ in $\mathrm{BS}$, although it is necessary to accumulate such evidence in younger cases $(40 \mathrm{~s}$ or $50 \mathrm{~s}$ in age) of Brugada-like ECG or BS with prostate cancer.

In conclusion, a higher risk of prostate cancer for Brugada-like ECG independent of age, smoking habit, and radiation exposure means that men with the Brugada-like ECG should be regularly examined for prostate cancer, especially elderly subjects. Likewise, prostate cancer patients should be routinely examined for the presence of Brugada-like ECG. Such actions might lead to earlier detection of prostate cancer in a small number of patients, but perhaps more importantly, might avoid arrhythmic events during surgical anesthesia for prostate cancer.

\section{Acknowledgments}

The Radiation Effects Research Foundation (RERF), Hiroshima and Nagasaki, Japan is a private, non-profit foundation funded by the Japanese Ministry of Health, Labour and Welfare (MHLW) and the US Department of Energy (DOE), the latter in part through the National Academy of Sciences. This publication was supported by RERF Research Protocol \#5-00. The authors thank Ms Kaoru Yoshida and Mr Tomohiro Ikeda for their help in preparation of the manuscript.

\section{References}

1. Brugada P, Brugada J. Right bundle branch block, persistent ST segment elevation and sudden cardiac death: A distinct clinical and electrocardiographic syndrome: A multicenter report. J Am Coll Cardiol 1992; 20: $1391-1396$.

2. Wilde AA, Antzelevitch C, Borggrefe M, Brugada J, Brugada R, Brugada P, et al. Proposed diagnostic criteria for the Brugada syndrome: Consensus report. Circulation 2002; 106: 2514-2519

3. Chen Q, Kirsch GE, Zhang D, Brugada R, Brugada J, Brugada P, et al. Genetic basis and molecular mechanism for idiopathic ventricular fibrillation. Nature 1998; 392: 293-296.

4. Makita N, Mochizuki N, Tsutsui H. Absence of trafficking defect in R1232W/T1620M, a double SCN5A mutant responsible for Brugada syndrome. Circ J 2008; 72: 1018-1019. 
5. Niimura $\mathrm{H}$, Matsunaga A, Kumagai $\mathrm{K}$, Ohwaki K, Ogawa M, Noguchi $\mathrm{H}$, et al. Genetic analysis of Brugada syndrome in Western Japan: Two novel mutations. Circ J 2004; 68: 740-746.

6. Matsuo K, Akahoshi M, Nakashima E, Suyama A, Seto S, Hayano $\mathrm{M}$, et al. The prevalence, incidence and prognostic value of the Brugada-type electrocardiogram, a population-based study of four decades. J Am Coll Cardiol 2001; 38: 765-770.

7. Shimizu W, Aiba T, Kamakura S. Mechanism and new findings in Brugada syndrome. Circ J 2007; 71(Suppl A): A-32-A-39.

8. Matsuo K, Akahoshi M, Seto S, Yano K. Disappearance of the Brugada-type electrocardiogram after surgical castration: A role for testosterone and an explanation for the male preponderance. Pacing Clin Electrophysiol 2003; 26: 1551-1553.

9. Shimizu W, Matsuo K, Kokubo Y, Satomi K, Kurita T, Noda T, et al. Sex hormone and gender difference-role of testosterone on male predominance in Brugada syndrome. J Cardiovasc Electrophysiol 2007; 18: $415-421$.

10. Nobel RL. The development of prostate adenocarcinoma in the $\mathrm{Nb}$ rat following prolonged sex hormone administration. Cancer Res 1977; 37: 1929-1933.

11. Henderson BE, Ross RK, Pike MC, Casagrande JT. Endogenous hormones as a major factor in human cancer. Cancer Res 1982; 42: $3232-3239$.

12. Atomic Bomb Casualty Commission. Research Plan for Joint ABCCNIH Adult Health Study in Hiroshima and Nagasaki: ABCC Technical Report. Hiroshima and Nagasaki, Japan, 1962; 11-62.

13. Akahoshi M, Soda M, Nakashima E, Shimaoka K, Seto S, Yano K. Effects of menopause on trends of serum cholesterol, blood pressure, and body mass index. Circulation 1996; 94: 61-66.

14. Matsuo K, Akahoshi M, Nakashima E, Seto S, Yano K. Clinical characteristics of subjects with the Brugada-type electrocardiogram: A case control study. J Cardiovasc Electrophysiol 2004; 15: 653 657.

15. Young R, Kerr G, editors. Reassessment of the atomic bomb radiation dosimetry for Hiroshima and Nagasaki, Dosimetry system 2002: Report for the Joint US-Japan Working Group. Hiroshima: Radiation Effects Research Foundation, 2005.

16. Pierce DA, Stram DO, Vaeth M. Allowing for random errors in radiation dose estimates for the atomic bomb survivor data. Radiat Res 1990; 123: 275-284

17. Preston DL, Pierce DA, Shimizu Y. Effect of recent changes in atomic bomb survivor dosimetry on cancer mortality risk estimates. Radiat Res 2004; 162: 377-389.

18. SAS/STAT software. Changes and Enhancement, Release 9.0. Cary, SAS Institute.
19. Plaskon LA, Penson DF, Vaughan TL, Stanford JL. Cigarette smoking and risk of prostate cancer in middle-aged men. Cancer Epidemiol Biomarkers Prev 2003; 12: 604-609.

20. Veierød MB, Laake P, Thelle DS. Dietary fat intake and risk of prostate cancer: A prospective study of 25708 Norwegian men. Int $J$ Cancer 1997; 73: 634-638.

21. Giovannucci E, Rimm E, Ascherio A, Corditz GA, Spieqelman D, Stampfer MJ, et al. Smoking and risk of total and fatal prostate cancer in United States health professionals. Cancer Epidemiol Biomarkers Prev 1999; 8: 277-282.

22. Thompson DE, Mabuchi K, Ron E, Soda M, Tokunaga M, Ochikubo $\mathrm{S}$, et al. Cancer incidence in atomic bomb survivors. Part II: Solid tumors, 1958-1987. Radiat Res 1994; 137(Suppl): S17-S67.

23. Preston DL, Ron E, Tokuoka S, Funamoto S, Nishi N, Soda M, et al. Solid cancer incidence in atomic bomb survivors: 1958-1998. Radiat Res 2007; 168: 1-64.

24. Yan GX, Antzelevitch C. Cellular basis for the Brugada syndrome and other mechanisms of arrhythmogenesis associated with STsegment elevation. Circulation 1999; 100: 1660-1666.

25. Shuba YM, Degtiar VE, Osipenko N, Naidenov VG, Woosley RL. Testosterone-mediated modulation of HERG blockage by proarrhythmic agents. Biochem Pharmacol 2001; 62: 41-49.

26. Liu XK, Katchman A, Whitfield BH, Wan G, Janowski EM, Woosley $\mathrm{RL}$, et al. In vivo androgen treatment shortens the QT interval and increases the densities of inward and delayed rectifier potassium current in orchiectomized male rabbits. Cardiovasc Res 2003; 57: $28-36$.

27. Bai CX, Kurosawa J, Tamagawa M, Nakaya H, Fukukawa T. Nontranscriptional regulation of cardiac repolarization currents by testosterone. Circulation 2005; 112: $1701-1710$.

28. Huggins C, Hodges CV. Studies on prostate cancer: Effect of castration, of estrogen, and of androgen injection on serum phosphatase in metastatic carcinoma of the prostate. Cancer Res 1941; 1: 293-297.

29. Gann PH, Hennekens CH, Ma J, Longcope C, Meir J, Stampfer MJ. Prospective study of sex hormone levels and risk of prostate cancer. J Natl Cancer Inst 1996; 88: 1118-1126.

30. Thompson IM, Goodman PJ, Tangen CM, Lucia MS, Miller GJ, Ford LG, et al. The influence of finasteride on the development of prostate cancer. $N$ Engl J Med 2003; 349: 215-224.

31. Nicole P, Mark P, Robert D, John B. Brugada-type electrocardiographic pattern induced by epidural bupivacaine. Anesth Analg 2003; 97: $264-267$.

32. Moller RA, Covino BG. Cardiac electrophysiologic effects of lidocaine and bupivacaine. Anesth Analg 1988; 67: 107-114. 